\title{
Defects of steel crane beams and methods of their strengthening
}

\author{
Andrei Shuryn ${ }^{1, *}$, Anatoli Mukhin ${ }^{1}$ and Alexandr Bryantsev ${ }^{2}$ \\ ${ }^{1}$ Brest State Technical University, 224017, Moskovskaya 267, Brest, Belarus \\ ${ }^{2}$ International Educational Corporation (KazGASA), 050043, Ryskulbekova 28, Almaty, Kazakhstan
}

\begin{abstract}
Crane structures are the most vulnerable in buildings and structures because of their early wear in comparison with other building structures. The wear of crane structures is because of the appearance and the development of fatigue damage nature.

The article presents the constructive solutions developed by the authors for strengthening the structures of steel crane beams with conventional and corrugated walls which allow to reduce the influence of the negative influence of installation, operation and technological processes on their operational durability.

The most dangerous installation defect is the displacement of the crane rail axis relative to the axis of the crane beams wall. Value of this shift is exceeded several times in the cases considered below. It is proposed to use crane beams with corrugated walls to solve this problem.

The authors have developed and implemented a project to restore the performance of steel crane beams by strengthening the walls of damaged beams without stopping production. Strengthening was performed on the outside of the eccentricities of the application of loads from crane rails by creating a truss structure parallel to the I-beam with chords of I-beams, which made it possible to significantly reduce the magnitude of local stresses from moments, the magnitude of transverse forces and consequently shear stresses, which are the main factors in the appearance and development of fatigue cracks in their walls.
\end{abstract}

Key words: crane structures, brake structures, steel crane beams, shear stresses.

\section{Introduction}

Crane structures are the most vulnerable in buildings and structures because of their early wear in comparison with other building structures. The term of their normal operation with direct participation in the production cycle is usually several times less than that of other structures. At the end of the service life, if reinforcement is impossible, replacement of damaged crane structures is required which is also not always possible because of the peculiarities of production processes.

The durability of building structures is significantly influenced by the features of crane effects, the presence of structural imperfections in the crane beams, as well as defects in

\footnotetext{
* Corresponding author: shuryn@mail.ru
} 
their manufacture and installation. The wear of the crane structures is also because of the appearance and development of fatigue damage. Multiple changes in the stress-strain state of crane structures lead to damage which significantly reduces their durability.

The article presents the constructive solutions developed by the authors to strengthen the structures of steel crane beams with conventional and corrugated walls, which make it possible to reduce the influence of the negative influence of installation, operation and technological processes on their service life.

\section{Methods}

During the production of certain types of products because of imperfection of technological processes or their violations there are deposits of industrial dust on brake structures which negatively affect the durability of not only crane structures but also crane wheels (Fig. 1).

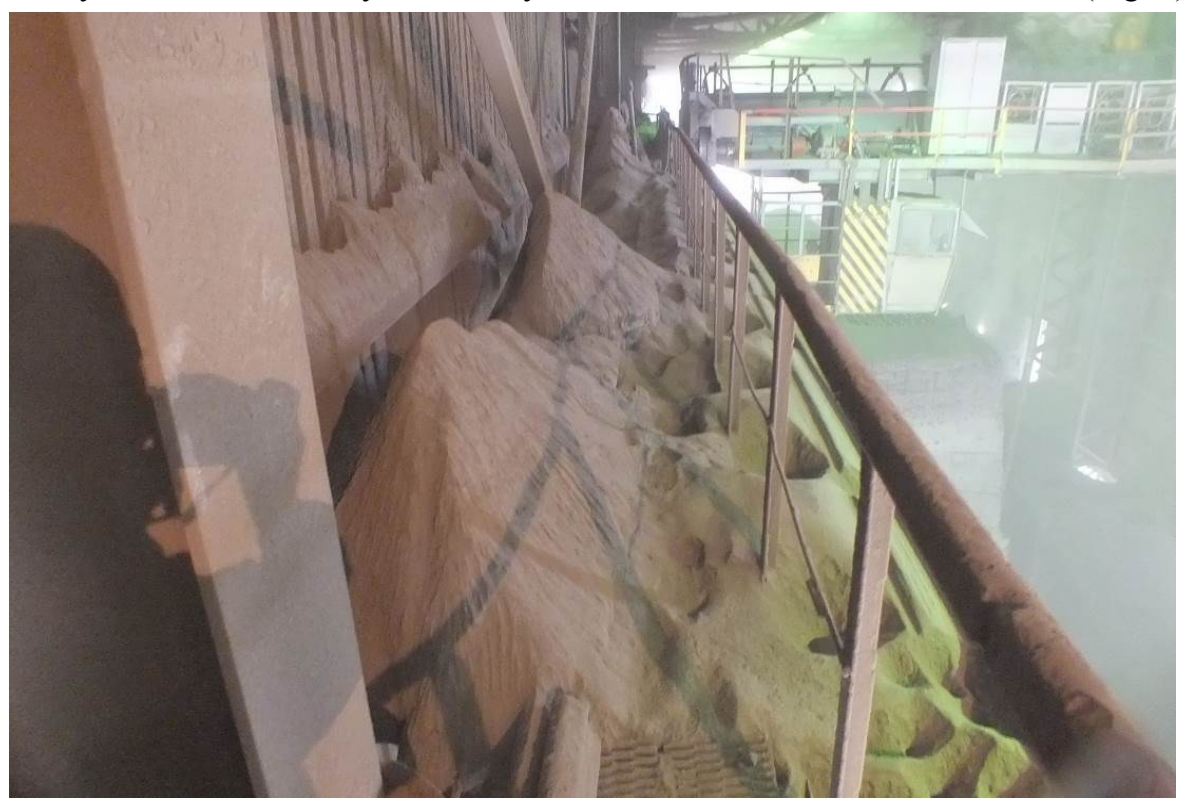

Fig. 1. Deposits of clinker on brake structures.

To prevent clinker accumulation on horizontal brake beams the authors recommend unloading them by installing holes in them. Work on the study of steel beams with walls with holes is currently underway in Kazakhstan. A round hole is possible at $\tau \leq 0.5 R_{s}$, but with a diameter of not more than half the height of the wall while the hole should be located in the center relative to the height of the wall which are bordered by angle or sheet steel reinforced by paired vertical stiffeners. The following design schemes can be used in the case of high lateral loads (Fig. 2).

A numerical parametric study of steel beams with a triangular corrugation shape [1] included the analysis of 55 beam models of which 1 beam model without a hole, 27 models with three holes in the wall and 27 models with two holes with a diameter of $0.25 \mathrm{~h}_{\mathrm{w}}, 0.5 \mathrm{~h}_{\mathrm{w}}$ and $0.75 \mathrm{~h}_{\mathrm{w}}$, spaced between the centers of holes $2 \mathrm{~d}, 3 \mathrm{~d}$ and $4 \mathrm{~d}$. Analysis of the operation of models of beams with three holes under a concentrated load and reinforced with edging and parallel stiffeners showed the efficiency of placing holes in the corrugated wall with a hole pitch of $2 \mathrm{~d}$ and with a hole diameter of $0.25 \mathrm{~h}_{\mathrm{w}}$ and $0.5 \mathrm{~h}_{\mathrm{w}}$ and for two holes reinforced with edging and parallel stiffeners, hole placement efficiency with hole spacing $2 \mathrm{~d}$ and $3 \mathrm{~d}$ and hole diameters $0.25 \mathrm{~h}_{\mathrm{w}}, 0.5 \mathrm{~h}_{\mathrm{w}}$ and $0.75 \mathrm{~h}_{\mathrm{w}}$. 
a)

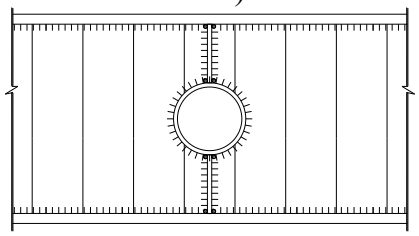

b)

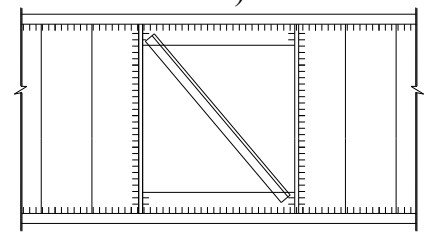

c)

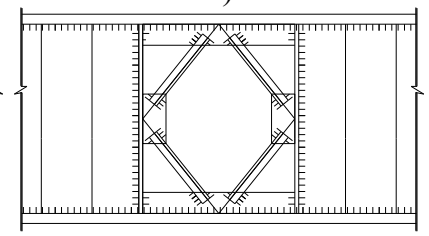

a) a hole reinforced with edging and stiffeners;

b) a hole reinforced with sheets and one brace from the corner;

c) a hole reinforced with a rhombic paired corner lattice.

Fig. 2. Constructive solutions for holes in corrugated walls.

In 2019, in the laboratory of KazGASA LLP (Almaty), on the load-bearing floor, 5 models of beams with corrugated walls (BGS-1,2,3,4,5) were tested, weakened by round technological holes with various reinforcement options holes [2]. Tests [3] were carried out according to a single-span scheme for lateral bending by a concentrated force applied in the middle of the span (Fig. 3) while the beams are based on the supports.

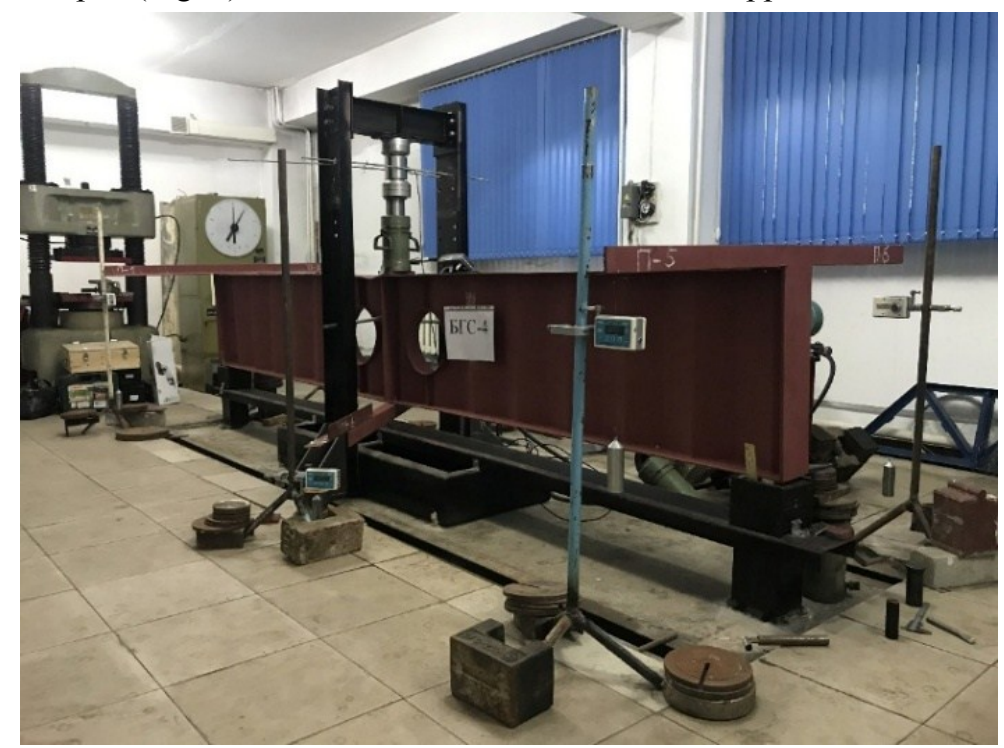

Fig. 3. General view of the installation for testing the BGS-4 beam.

Based on the research program and in accordance with the theory of optimal planning of experiments, 5 models were made, including 4 models with two round holes $0.5 \mathrm{hw}$ and a step between the centers of the holes $2 \mathrm{~d}$ [1] and 1 model without holes. The length of all beams is assumed to be $4.2 \mathrm{~m}$, the height of the walls is $0.6 \mathrm{~m}$, the wall thickness is $2 \mathrm{~mm}$, the width of the shelves is $0.15 \mathrm{~m}$, the thickness is $6 \mathrm{~mm}$. The effective step and high corrugation in accordance with the results of the third chapter of this dissertation work for a wall thickness of $2 \mathrm{~mm}$ were taken as $280 \times 45 \mathrm{~mm}$. In the course of the experiment on models with round bordered holes which are used in design practice for the passage of technological equipment within the height of beams the influence of various methods of reinforcing the holes on the bearing capacity and deformability of the models was investigated.

The reinforcement method described in SNiP RK 5.04-23-2020 "Steel structures" was chosen as the basis for reinforcing round holes, consisting of bordering the hole with sheet steel and installing paired vertical stiffeners on both sides of the wall (Fig. 4). 

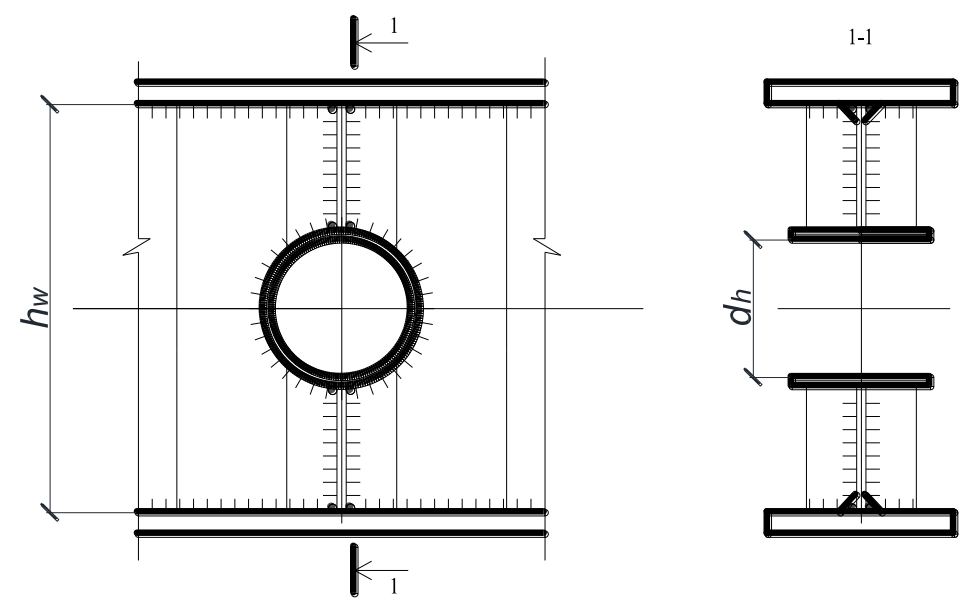

Fig. 4. Corrugated I-beam with a round hole bordered by sheet steel and paired vertical stiffeners.

This method, described in the regulatory documents of the Republic of Kazakhstan, does not contain specific data on the thickness of the metal for edging and stiffening ribs. Therefore, in the course of the study, it was determined that the most effective thickness of the edging and stiffeners for a hole with a diameter of $0.25 \mathrm{hw}$ and a step of $2 \mathrm{~d}$ is a thickness of 2 to $4 \mathrm{~mm}$; for a hole with a diameter $0.5 \mathrm{hw}$ and a step $2 \mathrm{~d}$, the thickness is from 4 to $6 \mathrm{~mm}$; for a hole with a diameter $0.75 \mathrm{hw}$ and a step $2 \mathrm{~d}$, the thickness is from 6 to $8 \mathrm{~mm}$.

Improved methods of reinforcing the holes were proposed during the study. Tests of beams together with finite element modeling allowed to draw conclusions about the effectiveness of improved methods of reinforcing circular holes [4, 5]. For the BGS-3 beam [4] reinforcement of the hole by bordering together with the thickening of the wall in the area of the hole by $2 \mathrm{tw}$ and for the BGS-5 beam [5] - the inclusion of an external bend of the border into the existing method of strengthening holes with stiffeners in accordance with the requirements SNiP II-23. Recommendations have been developed for introducing the two proposed options for strengthening the holes of the BGS-3 and BGS-5 models into the corresponding codes of rules (SP) or building codes (SN) and, thus, allowing to expand the range of issues of practical application.

The most dangerous installation defect is the displacement of the crane rail axis relative to the axis of the crane beam wall. In the cases considered below, the value of this displacement is exceeded several times which led to the need to develop special design solutions of an unconventional nature which made it possible to reduce the effect of this installation defect.

It can be used crane beams with corrugated walls to solve this problem. Kazakhstan has accumulated a lot of experience in the use of such beams (Fig. 5, 6).

In 2007, Kazakhstan put into operation a range of welded I-beams of the usual type and with corrugated walls RDS RK 6.04-24-2006 [6], developed by Institute Proektstalkonstruktsiya LLP which corresponds in strength characteristics to rolling I-beams according to STO ASChM 20-93, manufactured in Russia.

To assess the actual bearing capacity of welded I-sections with cross-corrugated walls of the new assortment in the laboratory of Institute Proektstalkonstruktsiya LLP, strength and stiffness tests were carried out for the types of welded I-beams given in the assortment (beam - BGS, wide-flange - ShGS and column - KGS I-beams) on full-scale samples. The experiments performed on large-scale models revealed the efficiency of using corrugated walls and made it possible to increase the cyclic durability by changing the corrugation parameters [6]. 


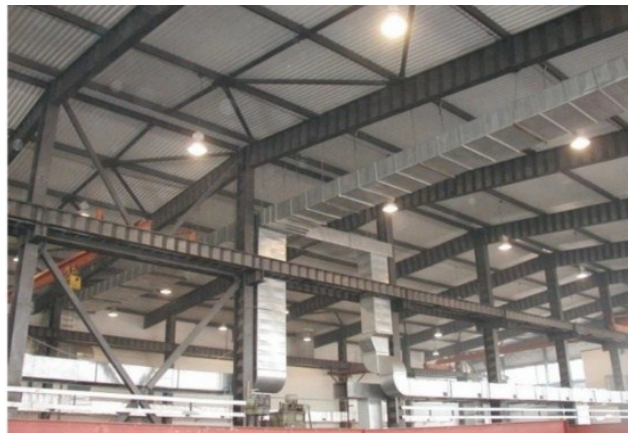

Fig. 5. One-story steel frame of the industrial building, in which the roof girders, columns and crane beams are made of welded I-beams with corrugated walls. Seismicity 10 points. 2007.

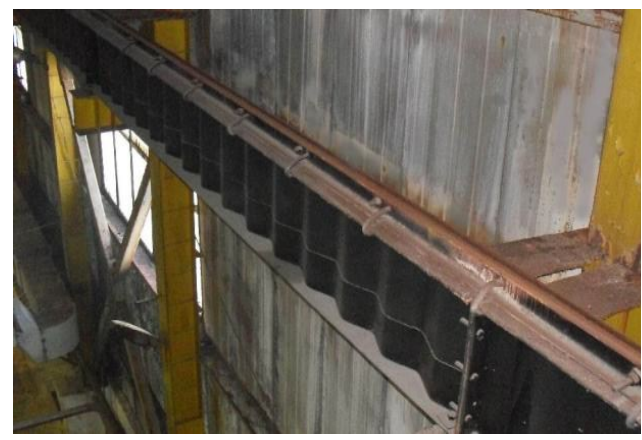

Fig. 6. Crane beams in the main building of the plant in Almaty region. The height of the beams is $640 \mathrm{~mm}$, the thickness of the corrugated walls is $6 \mathrm{~mm} .2001$.

\section{Results and Discussion}

Constructive solution for warehouse. The clinker warehouse of JSC Krasnoselskstroymaterialy is a one-storey one-span frame building with dimensions in the plan of $24 \times 317 \mathrm{~m}$. The frame is designed according to the frame-link scheme. The connection between the crossbar and the column and the columns with the foundations is rigid. The height to the lower chords of the trusses is $25.95 \mathrm{~m}$. The elevation of the crane rail head is $22.42 \mathrm{~m}$. The frame is mated at different elevations with other workshops associated with it by a single round-the-clock technological cycle. The building is equipped with three overhead cranes 16 ton lifting capacity with grabs.

The frame of the warehouse is formed of steel flat frames, including stepped columns, on which the steel crane beams with a span of 6 and 12 meters with brake beams are supported, steel trusses with a span of $24 \mathrm{~m}$ from rolled corners or bent-welded profiles. The trusses of the frame frames are rigidly connected to the columns, which are fixed in reinforced concrete foundations. Steel structures of the roof are united into a spatial system by a hard disk made of prefabricated ribbed reinforced concrete slabs, ties along the roof and along the columns.

Welded crane beams of the 1.426.2-3.1 series are used in the warehouse building, they were made of steel 09G2S-12-1 GOST 19281, with the exception of stiffening ribs, for which VSt3ps-7 is used in accordance with GOST 380. Crane beams with a span of $12 \mathrm{~m}$ have a cross section the upper belt is $-400 \times 14 \mathrm{~mm}$, the lower belt $-360 \times 10 \mathrm{~mm}$, the walls are $-1390 \times 12 \mathrm{~mm}$ (steel 09G2S-12-1 GOST 19281). Vertical stiffeners are installed along the length with a step of $1.5 \mathrm{~m}$. Beams with a span of $6 \mathrm{~m}$ have a cross-section of the upper belt $-400 \times 14 \mathrm{~mm}$, the lower belt $-250 \times 10 \mathrm{~mm}$, walls $-990 \times 10 \mathrm{~mm}$.

Technical expertise of steel crane beams. Examination and observation of the technical condition of the steel crane beams of the clinker warehouse of JSC "Krasnoselskstroimaterialy" have been carried out by the authors of the article since 2006 to the present. Violations of the requirements for the installation of crane structures were found. The survey results showed the presence of large eccentricities between the vertical axes of the rails and the axes of the walls of the crane beams, which should be attributed to defects in the installation of structures. The value of eccentricity for individual beams reached $70 \mathrm{~mm}$, which significantly exceeds the limit value of deviations for the rail axes of $15 \mathrm{~mm}$, provided for in TCP 45-5.04-49 [8]. The curvature of the crane girders in the horizontal plane reaches $30 \mathrm{~mm}$, which also exceeds the limiting values $\mathrm{f}=20 \mathrm{~mm}$ [9]. These defects, as well as the constant presence of clinker on the crane rails, cause wear of the crane wheels, 
damage to the crane rails, vertical and horizontal cracks in the walls of the crane beams which is accompanied in some cases by their destruction.

The features of the facility operation include the constant presence of a dust suspension of clinker ingredients in the air, due to the peculiarities of the technological process. These operations lead to dust deposits on all structural elements of the building. The height of dust deposits in some areas of the brake beams after the introduction of the dry cement production line in 2012 reaches $1.5 \mathrm{~m}$ (Fig. 1). This leads to the movement of the wheels of overhead cranes over a thin layer of clinker and distortions of the bridge of the crane during its movement along the building.

Defects and damages were found both in the frame structure and in the crane beams and their brake structures; significant wear of the crane wheel flanges and crane rails was noted. The most common defects in crane beams were fatigue cracks in their walls, which were found in $40 \%$ of crane beams. Cracks were found only at the ribs of the walls of the crane beams (Fig. 7).

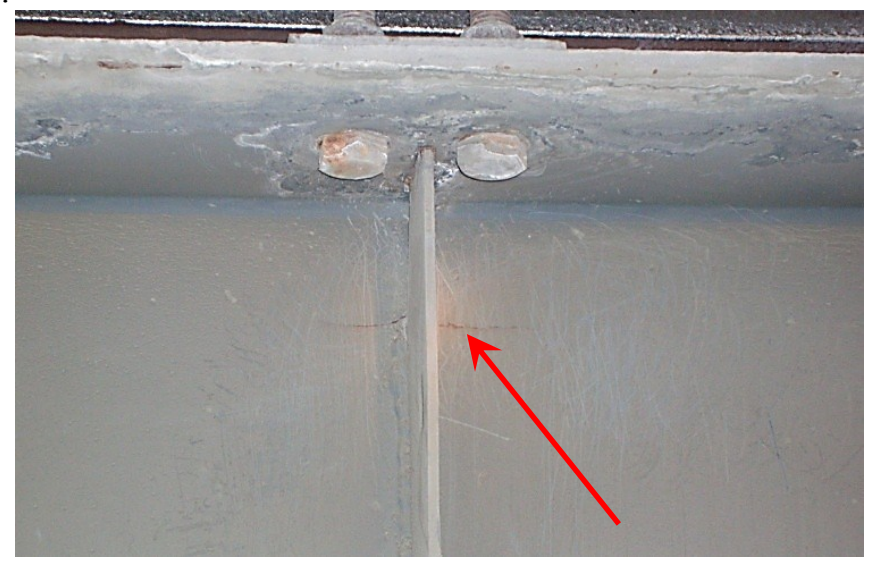

Fig. 7. Crack in the wall of the crane beam.

Defects in the form of cracks in the welded seams of brake structures, destruction of the beams-to-column attachment points were found in some beams. In accordance with the requirements [8], defects and damage of a significant and critical nature [10] in crane structures were eliminated by means of reinforcement.

During the technical examination of the crane beams carried out by the authors in 2009 and 2013 an increase in the number of damages was found some of which were of a critical nature. Cracks in the walls of the crane beams were found in $52 \%$ of the beams. New defects appeared in the form of local fractures of welded joints between brake structures and the upper flanges of crane beams (this defect was noted in $25 \%$ of crane beams).

It should be noted that when designing the clinker warehouse in accordance with GOST 25546-82 the operating mode of the cranes was taken as particularly difficult. In accordance with GOST 34017-2016, these overhead cranes have a utilization class of at least U7, the Q2 load class is light and, therefore, the A6 operating mode.

Verification calculations of crane structures carried out in accordance with the requirements of SNiP II-23 made it possible to establish that the main reason for the appearance of fatigue cracks in the walls was the presence of unacceptable eccentricities between the rail axes and the wall axes. The massive appearance of cracks in the walls of the crane beams was facilitated by the increased deformability of the frames caused by the lack of an assembly connection of the I-beams of the upper and lower parts of the individual columns of the frame along the A axis which also refers to installation defects of the frame structures.

Strengthening of the crane beams along the A axis. After 18 years of operation, fatigue cracks in the walls no more than $200 \mathrm{~mm}$ long and symmetrical with respect to the 
stiffeners were observed in $40 \%$ of the crane beams. It should be noted that the replacement of defective crane beams was immediately ruled out due to the peculiarities of the technological cycle of cement production. And the reinforcement of the walls by inclined lamellas led to the appearance of cracks in the welded seams of the lamellas in a period of 1-2 years after reinforcement.

To prevent clinker accumulation on horizontal brake beams, the authors recommended their unloading by arranging rectangular holes in them with edging and filling from meshes.

The authors developed and implemented a project to restore their operability by strengthening the walls of damaged steel beams without stopping production which made it possible to significantly reduce the stresses in walls of beams from the moment caused by the eccentricity of load application from the crane wheels. Reinforcement of the crane beams is made on the outside of the eccentricities of the application of loads from the crane rails by creating a truss structure parallel to the I-beam (Fig. 8). The truss belts are made of I-beams, the diagonal lattice is made of steel bent closed welded square profiles (GOST 30245).

The constructive solution of reinforcement made it possible to significantly reduce the magnitude of local stresses from moments, the magnitude of transverse forces and, consequently, shear stresses, which are the main factors in the appearance and development of fatigue cracks in their walls [7]. When the reinforced beams were re-examined along the A axis in 2017 after 8 years of operation, no new fatigue cracks were found in their walls.

Unloading of brake structures along the $B$ axis. 25 years after commissioning, in some crane beams of the clinker workshop along the B axis, frequent occurrence and rapid development of fatigue cracks began to be observed, followed by merging in adjacent compartments. Strengthening the walls of the crane beams with inclined and vertical overlays did not give a significant effect. An increase in the number of defects and damages in the brake structure of crane beams and their attachment points to the frame columns was also found.

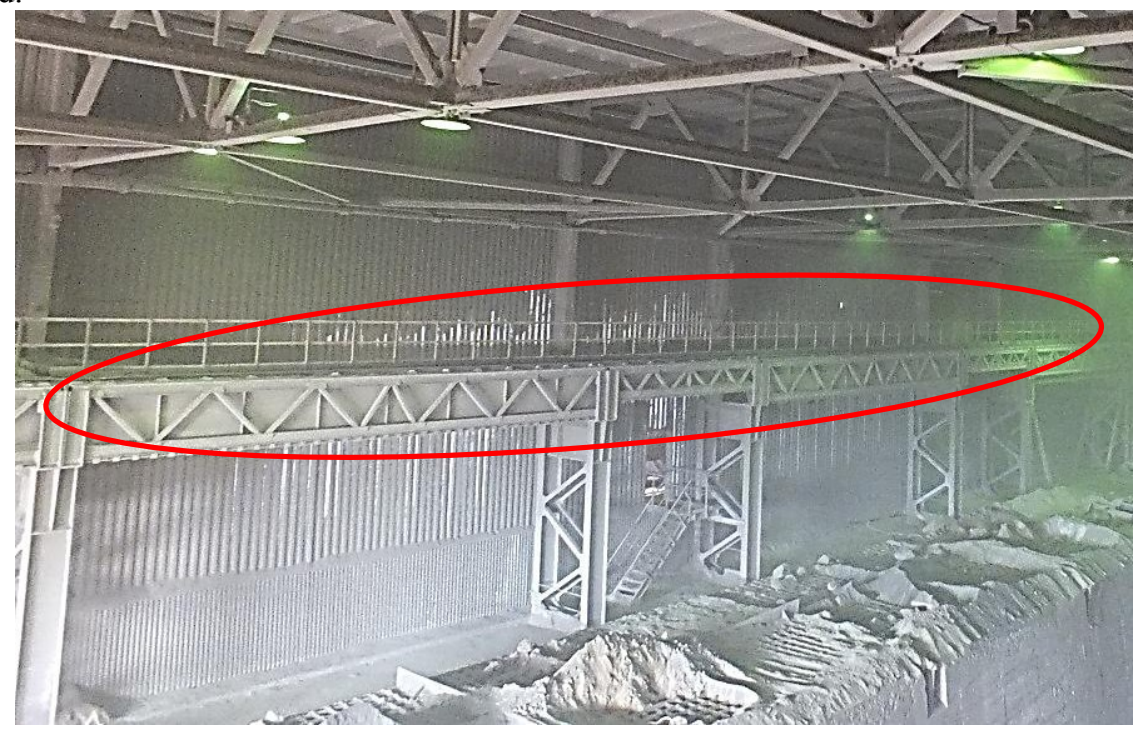

Fig. 8. General view of reinforced steel crane beams along the A axis with spans of 12 and $6 \mathrm{~m}$.

Based on the research carried out by the authors and to prevent clinker accumulation on horizontal brake beams with spans of 6 and $12 \mathrm{~m}$ the authors have developed a project that provides for making rectangular holes in them covered with a mesh of expanded metal sheets of PV 510 grade according to GOST 8706 or a steel mesh round hot-rolled $d=10$ 
$\mathrm{mm}$ in accordance with GOST 2590 with a cell of $90 \times 80 \mathrm{~mm}$ which is welded to frames made of rolled corners L50x5 in accordance with GOST 8509 (Fig. 9).

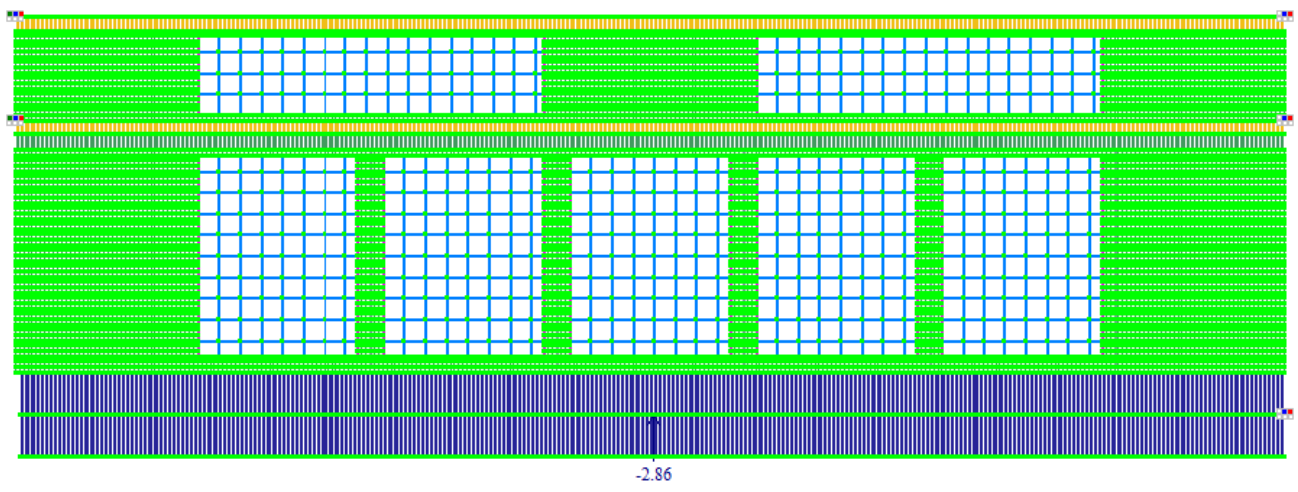

Fig. 9. Finite-element model of a brake beam with a span of $6 \mathrm{~m}$ with holes bordered by corners L50x5 in accordance with GOST 8509 and a mesh.

It has been established that the edging of holes filled from meshes or expanded steel in brake structures makes it possible to increase their endurance due to a decrease in horizontal displacements.

\section{Conclusions}

1. The strengthening of the steel crane beams developed by the authors by creating a truss structure parallel to the I-beam made it possible to significantly reduce the magnitude of local stresses from moments, the magnitude of transverse forces and, consequently, shear stresses which are the main factors in the appearance and development of fatigue cracks in their walls. When the reinforced beams were re-examined along the A axis in 2017 after 8 years of operation, no new fatigue cracks were found in their walls.

2. The authors have developed a project for unloading the brake beams by making bordered rectangular holes in them filled from meshes. The performed analysis of the stress-strain state of such a structure made it possible to establish:

- making holes in brake structures without edging increases the probability of fatigue cracks appearing in them;

- edging of holes in brake structures allows to increase their endurance due to a decrease in horizontal displacements by 2.5 times for BK 3 beams $6 \mathrm{~m}$ long and 5 times for BK1 beams 12 m long;

- a grid of cross bars made of round hot-rolled steel $\mathrm{d}=10 \mathrm{~mm}$ in accordance with GOST 2590 with a cell of 90x80 mm, welded to frames made of rolled corners L50x5 in accordance with GOST 8509, allowed to reduce horizontal deformations of beams by 1.25 times compared with a grid of expanded metal sheets grade PV 510 in accordance with GOST 8706.

\section{References}

1. A.A. Bryantsev, V.E. Absimetov, V.V. Lalin, Magazine of Civil Engineering. 87(3). The effect of perforations on the deformability of welded beam with corrugated webs. pp. 18-34 (2019)

2. A.A. Bryantsev, Vestnik Kazntu. Almaty. 5. Full-scale tests of welded corrugated beams with round holes. Vestnik Kazntu. pp. 261-268 (2019) 
3. A.A. Bryantsev, V.E. Absimetov, Environmental and Construction Engineering. 70. Laboratory tests of welded corrugated beams with perforations. Lecture Notes in Civil Engineering. Proceedings of EECE 2019. Energy, pp. 55-67 (2020)

4. Patent 4318 Republic of Kazakhstan, I-beam with reinforced holes / Bryancev A.A. № 2019/0422.2, publ. 18.09.2019

5. Patent 4540 Republic of Kazakhstan, I-beam with reinforced holes / Bryancev A.A. № 2019/0774.2, publ. 11.12.2019

6. RDS RK 5.04-24-2006. Mix of fabricated i-beam sections of regular type and with corrugated walls meeting strength properties of rolling sections. - TOO «Institut Proektstal'konstrukciya». 20 (2007)

7. K.K. Nezhdanov, A.S. Lashtankin, I.N. Gar'kin, Structural Mechanics and Analysis of Constructions. Novosibirsk. 3. Teams crane beams of rolled profiles, pp. 69-74 (2013)

8. TKP 45-5.04-49-2007. Steel designs. Inspection and diagnostics of a technical condition. Ministry of Architecture and Construction of the Republic of Belarus. 127. (2008)

9. Guidelines for refurbishment of crane structures. USSR Ministry of Metallurgy. 118 (1991)

10. TKP 45-1.04-305-2016. Technical condition and maintenance of buildings and facilities Basic requirements. Ministry of Architecture and Construction of the Republic of Belarus. 107 (2017) 